\title{
Pembelajaran dengan pemodelan untuk meningkatkan pemahaman konsep getaran pada siswa kelas VIII
}

\author{
Wahyulia Diah Arum Trisnawati, Sutopo*, Erni Yulianti \\ Universitas Negeri Malang, Jl. Semarang No. 5 Malang, Jawa Timur, Indonesia \\ *Penulis korespondensi, Surel: sutopo.fisika@um.ac.id
}

Paper received: 01-04-2021; revised: 15-04-2021; accepted: 30-04-2021

\begin{abstract}
Abstrak
Pembelajaran IPA menuntut siswa harus memahami konsep serta keterkaitannya untuk menyelesaikan masalah. Siswa sering mengalami kesulitan dalam memahami konsep, untuk itu dibutuhkan desain pembelajaran yang tepat untuk mengatasi kesulitan tersebut. Penelitian ini bertujuan untuk mengetahui keterlaksanaan dan efektifitas pembelajaran dengan pemodelan terhadap pemahaman konsep siswa pada topik getaran. Penelitian ini menggunakan mixed method jenis embedded experiment. Subjek penelitian adalah siswa kelas VIII-C MTs YTP Kertosono tahun pelajaran 2016/2017. Untuk mengetahui kekuatan peningkatan skor pretest ke posttest diukur dengan $d$-effect size dan $\mathrm{N}$-gain ternormalisasi. Hasil penelitian menunjukkan bahwa pembelajaran dengan pemodelan dapat meningkatkan pemahaman konsep siswa pada topik getaran dengan $d$ effect size 1,582 termasuk dalam kategori sangat tinggi efektifitasnya, dan $N$-gain 0,508 termasuk dalam kategori medium atas peningkatan pretest ke posttest. Sehingga dapat dikatakan bahwa pembelajaran dengan pemodelan ini sangat efektif digunakan untuk meningkatkan pemahaman konsep siswa pada topik getaran.
\end{abstract}

Kata kunci: pembelajaran dengan pemodelan; konsep getaran; pemahaman konsep

\section{Pendahuluan}

IPA diperlukan dalam kehidupan sehari-hari untuk memenuhi kebutuhan manusia melalui penyelesaian masalah-masalah yang dapat diidentifikasi. Kompetensi mata pelajaran IPA yang harus dimiliki oleh siswa SMP adalah memahami konsep dan prinsip IPA serta keterkaitannya dalam menyelesaikan masalah (Permendikbud No. 21 Tahun 2016).

Getaran termasuk topik yang banyak berkaitan dengan lingkungan serta berhubungan dengan fenomena-fenomena yang terjadi di kehidupan sehari-hari siswa. Beberapa contohnya adalah kentongan yang dipukul akan bergetar, gamelan yang dipukul akan bergetar, penggaris yang digetarkan akan bergetar ke atas dan ke bawah, sinar gitar yang dipetik akan bergetar, dan lain sebagainya. Berdasarkan peristiwa yang dialami dan dilihat oleh siswa setiap hari, membuat siswa memiliki pemahaman awal yang berkembang dari pengalaman. Pemahaman awal yang siswa miliki terkadang ada yang kurang sesuai. Pemahaman yang tidak sesuai dengan para ahli disebut salah konsepsi atau miskonsepsi. Beberapa peneliti pendidikan menyebut miskonsepsi dengan berbagai istilah, diantaranya kesalahan, ide yang menyesatkan, kesalah pahaman, atau kesalahan dalam menginterpretasikan fakta (Baser, 2006; Alwan, 2011).

Miskonsepsi dan kesulitan siswa pada konsep getaran ditemukan pada beberapa penelitian sebelumnya. Sutopo (2012) mengungkapkan bahwa siswa mengalami salah penerapan prinsip resonansi kolom udara untuk memecahkan persoalan yang berkaitan dengan sumber bunyi. Hamdani (2007) mengungkapkan bahwa sebagian besar siswa menganggap bahwa hanya massa yang mempengaruhi frekuensi pada ayunan, serta menganggap bahwa frekuensi pada pegas dipengaruhi oleh massa dan amplitudonya. Kiftiyah, Yudiyanto, \& Sutopo (2014) mengungkapkan bahwa sebagian besar siswa 
menganggap bahwa periode dan frekuensi pada ayunan hanya dipengaruhi oleh massa dan amplitudo. Padang, Munzil, \& Hidayat (2016) mengungkapkan bahwa rata-rata skor pemahaman konsep siswa masih berada pada kategori rendah. Dari beberapa penelitian tersebut dapat disimpulkan bahwa siswa masih mengalami kesulitan dalam memahami konsep getaran, sehingga perlu dilakukan penelitian untuk mengatasi hal ini.

Sejumlah peneliti telah melakukan penelitian untuk mengatasi miskonsepsi pada materi getaran dengan beberapa model pembelajaran (Wahyudin, Sutikno \& Isa, 2010; Ponimin, 2010; Septa \& Khoiri, 2010; Samiyah, Sutopo, \& Sutarman, 2015; Widiastuti \& Yulianti, 2016), namun peningkatan penguasaan konsepnya belum optimal. Penelitian yang telah dilakukan terbukti efektif dalam mengembangkan pemahaman siswa, namun masih meninggalkan beberapa masalah terkait materi getaran. Melalui beberapa temuan tersebut, guru perlu merancang suatu pembelajaran yang dapat mengatasi kelemahan-kelemahan yang ada. Dengan desain pembelajaran yang tepat, siswa dapat dibantu untuk memahami konsep getaran dan model matematis untuk mempresentasikan prinsip tersebut. Pembelajaran yang dimaksud di sini adalah pembelajaran dengan pemodelan.

Pembelajaran dengan pemodelan merupakan pembelajaran bersifat eksperimental dan penyelidikan yang melibatkan siswa secara aktif untuk mengembangkan pemahaman (Halloun, 2007). Melalui pemodelan, siswa dapat mengembangkan kemampuan dalam membuat penjelasan ilmiah dari fenomena yang dipelajari. Kemampuan mengembangkan model dan penjelasan berdasarkan bukti adalah kemampuan yang penting untuk dikembangkan siswa melalui belajar sains (NRC, 2012).

Pembelajaran dengan pemodelan terdiri dari dua tahap utama, yaitu pengembangan model (model development) dan penerapan model (model deployment). Pengembangan model dapat dimulai dengan demonstrasi dan dilanjutkan dengan diskusi kelas (Hestenes, 1987). Dalam tahap ini siswa mengembangkan model matematis dari fenomena yang dihadirkan dalam demonstrasi, melalui diskusi kelompok dan mengevaluasi model yang dibuat dengan membandingkan data yang diperoleh dari percobaan dan diskusi. Pada penerapan model, siswa menerapkan model baru yang diperolehnya pada situasi baru yang bertujuan untuk memperbaiki dan memperdalam pemahaman (Jackson, Duerich, \& Hestenes, 2008). Penerapan model ini adalah kegiatan mengaplikasikan model yang telah diperolehnya pada situasi atau masalah baru, kehidupan sehari-hari atau soal (Hestenes, 1987; Wells, Hestenes, \& Swackhamer, 1995).

Kualitas model yang dibuat siswa sangat bergantung pada pengetahuan awal dan pemahaman siswa tentang sistem yang dimodelkan. Melalui pembelajaran pemodelan diharapkan siswa terus memperbaiki model yang dibuatnya seiring perkembangan pemahamannya (Jackson, Duerich, \& Hestenes, 2008; NRC, 2012).

Pembelajaran dengan pemodelan diharapkan mampu memberikan pengalaman secara langsung sehingga siswa mampu memahami konsep dengan model yang telah diperoleh dan dapat menerapkannya untuk menyelesaikan suatu permasalahan dalam situasi baru. Beberapa penelitian menunjukkan bahwa pembelajaran dengan pemodelan efektif dalam meningkatkan pemahaman siswa (Wells, Hestenes, \& Swackhamer, 1995; Meltzer dan Manivannan, 2002; Jackson, Duerich, \& Hestenes, 2008; Brewe, dkk., 2010), dan juga dapat meningkatkan sikap belajar siswa (Brewe, 2008; Brewe, Kramer, \& O’Brien, 2009; Brewe, dkk., 2010). 


\section{Metode}

Penelitian ini menggunakan rancangan penelitian mixed methods dengan tipe embedded experiment. Desain embedded experiment menggunakan data kualitatif yang digabungkan pada metode eksperimen, desain penelitian dapat dilihat pada Gambar 1. Metode eksperimen sebagai fokus utama sedangkan kualitatif sebagai pendukung atau pelengkap dalam penelitian. Pendeskripsian proses pembelajaran memerlukan data kualitatif sedangkan untuk mengetahui keefektifan pembelajaran diperlukan data kuantitatif berupa pretest dan posttest dan data kualitatif hasil wawancara dengan siswa yang mengalami ketidakpahaman.

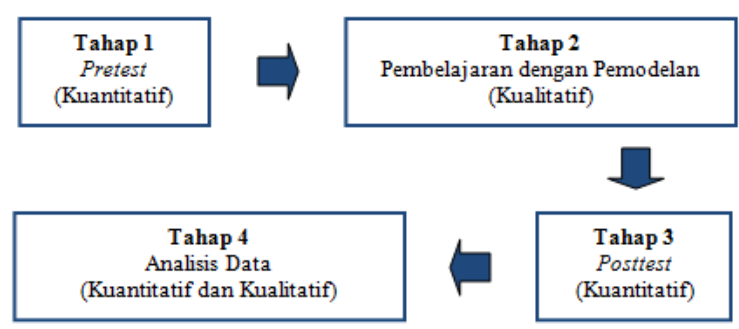

\section{Gambar 1. Tahap-tahap Pelaksanaan Penelitian Mixed Method dengan Embedded Experiment Design}

\section{(Sumber: Creswell, 2008)}

Penelitian ini dilaksanakan dalam 4 tahap. Tahap pertama adalah mengetahui pengetahuan awal siswa dengan memberikan pretest berupa soal pilihan ganda. Tahap kedua adalah penerapan pembelajaran pemodelan matematis pada topik getaran. Pada saat pembelajaran digunakan RPP dan LKS sebagai pedoman. Tahap ketiga adalah melakukan posttest, untuk mengetahui pemahaman konsep siswa setelah mengikuti pembelajaran. Soal yang digunakan saat posttest sama seperti soal pretest. Tahap keempat adalah menganalisis hasil pretest dan posttest sehingga diketahui pengaruh pembelajaran yang telah dilakukan.

Subjek penelitian adalah kelas VIII-C MTs YTP Kertosono. Penelitian dilaksanakan pada 17-20 April 2017. Instrumen penelitian berupa soal tes dan lembar observasi keterlaksanaan. Teknik pengumpulan data dilakukan dengan tes yang terdiri dari 16 butir soal pilihan ganda yang valid dengan reliabilitas sebesar 0.805 , teknik observasi, dan wawancara. Uji prasyarat yang dilakukan adalah uji normalitas dengan melihat nilai skewness. Setelah memenuhi uji prasyarat maka dilakukan uji-t, dan dilanjutkan dengan mengitung nilai $d$-effect size dan $\mathrm{N}$-gain ternormalisasi.

\section{Hasil dan Pembahasan}

Hasil penelitian berupa deskripsi pelaksanaan pembelajaran dengan pemodelan dan data tentang pemahaman konsep siswa yang dibagi menjadi dua, yaitu data pretest dan data posttest. Data hasil pretest siswa disajikan pada Tabel 1.

Tabel 1. Data Pretest Siswa

\begin{tabular}{ll}
\hline Statistics & Pretest \\
\hline $\mathrm{N}$ & 29 \\
Mean & 7,38 \\
Std. Deviation & 2,41 \\
Skewness &,- 317 \\
\hline
\end{tabular}




\begin{tabular}{ll}
\hline Std. Error of Skewness &, 434 \\
Minimum & 3,00 \\
Maximum & 12,00 \\
\hline
\end{tabular}

Tabel 1 menunjukkan data hasil pretest siswa bahwa skor rata-rata siswa sebesar 7,38 dengan standar deviasi sebesar 2,14. Nilai skewness yang diperoleh sebesar -0,317 dengan standar error sebesar 0,434. Hal ini menunjukkan data terdistribusi normal.

Pelaksanaan pembelajaran dengan pemodelan yang dilakukan oleh siswa diawali dengan kegiatan demonstrasi tentang getaran pada sistem pegas massa yang dilakukan oleh guru. Selanjutnya siswa mendeskripsikan dan membuat pola model matematis dari fenomena yang diamati dari demonstrasi secara berdiskusi kelompok. Setelah dapat membuat polanya, siswa menyampaikan pola model matematis yang telah dibuatnya dan dilakukan diskusi klasikal. Dilanjutkan dengan kegitan percobaan untuk menemukan persamaan matematis dari getaran sistem pegas-massa. Dengan model matematis ini diharapkan dapat digunakan untuk digunakan dalam menyelesaikan permasalahan baru yang berkaitan dengan konsep yang telah dipelajari. Kegiatan selanjutnya adalah penerapan model yang telah dibuat dengan mengerjakan soal-soal aplikatif. Selama pembelajaran siswa secara aktif bertanya, menjawab dan melakukan percobaan.

Pembelajaran dengan pemodelan merupakan pembelajaran eksperimental dan penyelidikan yang melibatkan siswa secara aktif untuk mengembangkan pemahaman (Halloun, 2007). Peran guru dalam pembelajaran adalah sebagai fasilitator dan mengawasi jalannya pembelajaran. Guru meluruskan konsep yang salah ketika siswa sedang melakukan pembelajaran. Selain itu, guru bertindak membantu siswa untuk memahami gagasan berdasarkan bukti empiris dan sesuai dengan teori ilmiah dan prakteknya (Halloun, 2007).

Pembelajaran pemodelan ini adalah proses kognitif yang menerapkan prinsip perancangan teori untuk menghasilkan model matematis. Proses kognitif ini disebut dengan model development atau pemodelan sederhana (Hestenes, 1987). Dalam tahap ini siswa mengembangkan model matematis dari demonstrasi dan deskripsi konsep yang dilakukan pada awal pembelajaran. Setelah dikembangkan model matematis yang tepat, model tersebut digunakan untuk memecahkan permasalah yang sesuai dengan fenomena atau peristiwa yang dihadapi. Tahap ini termasuk dalam model deployment atau penerapan model (Hestenes, 1987). Selain untuk menjelaskan penerapan model pada berbagai situasi, pemodelan juga dapat digunakan untuk memprediksi kejadian fisik atau untuk merancang eksperimen (Hestenes, 1997).

Pada tahap penerapan model, siswa menerapkan model yang diperolehnya dari tahap pertama pada permasalahn baru. Pada tahap ini bertujuan untuk memperbaiki dan memperdalam pemahaman siswa (Jackson, Dukerich, \& Hestenes, 2008). Melalui pembelajaran pemodelan ini siswa dapat memecahkan permasalahan dengan menggunakan model matematis yang telah ditemukan saat pembelajaran. Siswa dapat menyajikan model eksplisit untuk menjelaskan situasi fisik melalui pembelajaran menggunakan pemodelan. Siswa tidak hanya mampu menjawab pertanyaan namun juga mampu menjelaskan alasan mereka mendapatkan jawaban tersebut dan menghubungkannya dengan model yang telah dibuat. Sehingga melalui pembelajaran ini siswa dapat mengalami peningkatan pemahaman secara utuh dan menyeluruh (Wells, Hestenes, \& Swackhamer, 1995). 
Setelah pembelajaran dengan pemodelan selesai dilaksanakan selanjutnya dilakukan posttest. Posttest dilaksanakan sehari setelah pembelajaran di kelas. Data hasil posttest dapat dilihat pada Tabel 2.

Tabel 2. Data Posttest Siswa

\begin{tabular}{ll}
\hline Statistics & Posttest \\
\hline $\mathrm{N}$ & 29 \\
Mean & 11,76 \\
Std. Deviation & 3,12 \\
Skewness &,- 401 \\
Std. Error of &, 434 \\
Skewness & \\
Minimum & 5,00 \\
Maximum & 16,00 \\
\hline
\end{tabular}

Tabel 2 menunjukkan bahwa skor rata-rata siswa saat posttest sebesar 11,76 dengan standar deviasi 3,12. Nilai skewness yang diperoleh sebesar -0,401 dengan standar error sebesar 0,434. Hal ini menunjukkan bahwa data terdistribusi normal. Jika dibandingkan dengan hasil pretest pada Tabel 1, maka dapat diketahui bahwa terjadi peningkatan rata-rata skor yang diperoleh sebelum dengan sesudah dilakukan pembelajaran dengan pemodelan.

Berdasarkan hasil analisis data pretest dan posttest siswa dapat diketahui bahawa rata-rata skor siswa mengalami peningkatan. Berikut disajikan grafik sebaran (scatter plot) yang menunjukkan persebaran skor yang didapat siswa pada pretest dan posttest.

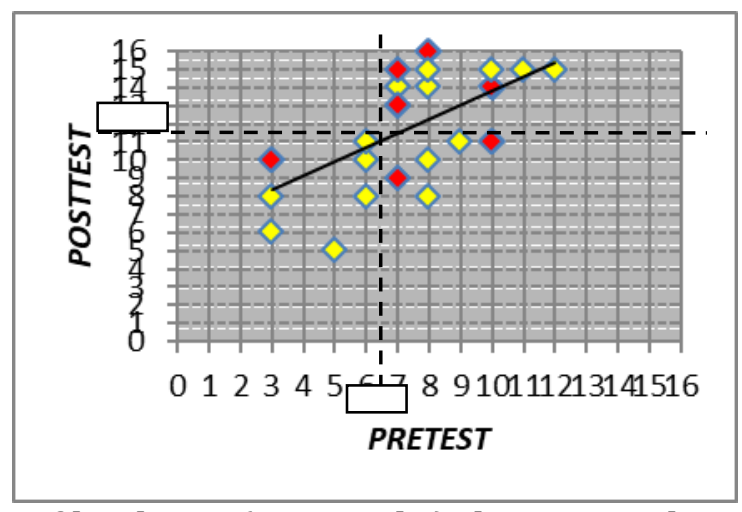

Gambar 2. Grafik Sebaran (Scatter Plot) Skor Pretest dan Posttest Siswa

Keterangan :

$$
\diamond: 1 \text { Orang Siswa }
$$

Berdasarkan grafik sebaran tersebut dapat diketahui bahwa secara keseluruhan siswa mengalami peningkatan skor tes, hanya terdapat 2 siswa yang tidak mengalami perubahan skor tes.

Berdasarkan analisis jawaban tes siswa, alasan jawabannya, serta kegiatan wawancara terhadap beberapa siswa menunjukkan bahwa pembelajaran dengan pemodelan mampu meningkatkan pemahaman konsep getaran pada siswa. Hal ini ditunjukkan dengan peningkatan jumlah skor jawaban benar setiap siswa. Hasil analisis uji-t juga menunjukkan 
bahwa terdapat beda secara signifikan pemahaman konsep siswa sebelum dan setelah pembelajaran. Kekuatan peningkatan pemahaman konsep siswa dari pretest ke posttest ditunjukkan dengan nilai $\mathrm{N}$-gain rata-rata 0,508. Nilai ini termasuk pada kategori mediumatas (Sutopo \& Waldrip, 2013). Nilai $d$-effect size sebesar 1,582. Nilai ini termasuk kategori tinggi sekali (Morgan, dkk., 2004).

Peningkatan pemahaman dapat terjadi karena berdasarkan observasi menunjukkan bahwa sebagian besar siswa fokus dan memperhatikan pembelajaran yang dilakukan di kelas. Siswa melakukan demonstrasi, merespon dan mendeskripsikan demonstrasi tersebut, menentukan pemodelan matematis dari hasil deskripsi dan percobaan yang telah dilakukan siswa sendiri. Siswa aktif untuk menemukan konsep dan model matematis selama pembelajaran. Pengalaman secara langsung dalam pembelajaran dapat menjadikan siswa lebih memahami materi. Pembelajaran seperti ini dapat mengembangkan kemampuan dalam membuat penjelasan ilmiah dari fenomena yang dipelajari. Kemampuan mengembangkan model dan penjelasan berdasarkan bukti adalah kemampuan yang penting untuk dikembangkan siswa melalui belajar sains (NRC, 2012). Keberhasilan dalam pembelajaran ditunjukkan dengan terjadinya perubahan dalam diri siswa yang disebabkan oleh pengalaman (Slavin, 2011: 177).

Berdasarkan penelitian ini terlihat bahwa masih terdapat beberapa siswa yang belum memahami penerapan konsep secara utuh dan masih terdapat siswa yang belum mengalami peningkatan pemahaman konsepnya. Kesulitan yang dialami siswa dimungkinkan karena materi yang diajarkan masih tergolong abstrak, sehingga siswa susah untuk memahaminya. Berdasarkan hal tersebut ternyata pembelajaran yang diberikan belum sepenuhnya memberikan hasil yang optimal untuk meningkatkan pemahaman konsep siswa. Namun secara keseluruhan pembelajaran dengan pemodelan ini mampu meningkatkan pemahaman konsep siswa pada topik getaran. Dari sejumlah penelitian yang telah dilakukan, pembelajaran dengan pemodelan ini efektif dalam meningkatkan pemahaman siswa (Wells, Hestenes, \& Swackhamer, 1995; Meltzer \& Manivannan, 2002; Jackson, Dukerich, \& Hestenes, 2008; Brewe, dkk., 2010). Selain pemahaman siswa, pembelajaran ini juga dapat meningkatkan sikap belajar siswa (Brewe, 2008; Brewe, Kramer, \& O’Brien, 2009; Brewe, dkk., 2013).

Hasil penelitian ini didukung oleh penelitian sebelumnya, yaitu penelitian yang menunjukkan bahwa siswa yang melaksanakan pembelajaran dengan pemodelan mengalami peningkatan pada aspek pemahaman konsep fisika prinsip persamaan keadaan gas (Adila, Sutopo, \& Prayekti, 2016). Selain itu, penelitian yang dilakukan oleh Windasari, Sutopo, \& Sulur (2017) menyimpulkan bahwa pembelajaran dengan pemodelan dapat meningkatkan pemahaman konsep siswa pada prinsip Archimedes.

Penelitian lain menyatakan bahwa siswa yang belajar dengan metode pemodelan mengalami peningkatan pemahaman konsep lebih baik daripada yang belajar dengan pembelajaran tradisional (Helmi, Diantoro, \& Suyudi, 2011). Penelitian lain yang mendukung adalah penelitian yang dilakukan oleh Suswati, Wartono, \& Muhardjito (2012) menyimpulkan bahwa hasil belajar untuk kelompok siswa yang mengikuti pembelajaran dengan pemodelan lebih tinggi daripada hasil belajar untuk kelompok siswa yang mengikuti pembelajaran secara konvensional. 
Berdasarkan dari uraian diatas maka dikatakan hasil penelitian ini menunjukkan bahwa terdapat peningkatan pemahaman konsep siswa setelah melakukan pembelajaran dengan pemodelan. Hal ini ditunjukkan dengan nilai rata-rata gain ternormalisasi kelas sebesar 0,508 termasuk kategori medium-atas. Pembelajaran dengan pemodelan ini memiliki dampak sangat tinggi untuk meningkatkan pemahaman konsep siswa. Hal ini ditunjukkan dengan nilai $d$-effect size sebesar 1,582 yang termasuk sangat tinggi. Sehingga dapat dikatakan bahwa pembelajaran dengan pemodelan ini sangat efektif digunakan untuk meningkatkan pemahaman konsep siswa pada topik getaran.

\section{Simpulan}

\subsection{Kesimpulan}

Berdasarkan analisis dan pembahasan yang telah diuraikan sebelumnya, diperoleh kesimpulan sebagai berikut.

Pembelajaan IPA pada topik getaran dengan pemodelan melalui 2 tahap yaitu tahap pengembangan model dan tahap penerapan model. Tahap pengembangan model dilakukan melalui kegiatan demonstrasi, diskusi dan percobaan. Tahap penerapan model dilakukan dengan cara mengaplikasikan model matematis yang telah diperoleh untuk mengerjakan soal dan pertanyaan aplikatif .

Pembelajaran dengan pemodelan dapat meningkatkan pemahaman konsep getaran pada siswa kelas VIII C MTs YTP Kertosono dengan nilai $d$-effect size 1,582 termasuk dalam kategori sangat tinggi efektifitasnya, dan nilai $\mathrm{N}$-gain rata-rata pretest ke posttest sebesar 0,508 termasuk dalam kategori medium atas. Sehingga dapat dikatakan bahwa pembelajaran dengan pemodelan ini sangat efektif digunakan untuk meningkatkan pemahaman konsep siswa pada topik getaran.

\subsection{Saran}

Berdasarkan analisis dan pembahasan hasil penelitian maka dapat dikemukakan saran sebagai berikut.

Pembelajaran dengan pemodelan memerlukan waktu yang cukup lama untuk membantu siswa menemukan konsep dengan pemodelan, sehingga guru sebaiknya menambahkan pertanyaan-pertanyaan konsep sebagai bahan diskusi di luar kelas untuk meningkatkan pemahaman siswa terhadap materi.

Pemahaman konsep hubungan massa beban, konstanta pegas dan frekuensi masih perlu diperbaiki, dan perlunya penekanan beberapa syarat agar hubungan antara besara-besaran persamaan frekuensi getaran pada pegas dapat berlaku sehingga perlu dikembangkan strategi pembelajaran yang dapat mengatasi kesulitan tersebut.

\section{Daftar Rujukan}

Adila, A. S. D. (2016). Pembelajaran dengan pemodelan untuk meningkatkan pemahaman konsep fisika siswa kelas XI tentang persamaan keadaan gas (Doctoral dissertation, Universitas Negeri Malang).

Alwan, A. A. (2011). Misconception of heat and temperature among physics students. Procedia-Social and Behavioral Sciences, 12, 600-614. 
Baser, M. (2006). Effect of Conceptual Change Oriented Instruction on Students' Understanding of Heat and Temperature Concepts. Online Submission, 4(1), 64-79.

Brewe, E. (2008). Modeling theory applied: Modeling Instruction in introductory physics. American Journal of physics, 76(12), 1155-1160.

Brewe, E., Kramer, L., \& O’Brien, G. (2009). Modeling instruction: Positive attitudinal shifts in introductory physics measured with CLASS. Physical Review Special Topics-Physics Education Research, 5(1), 013102.

Brewe, E., Sawtelle, V., Kramer, L. H., O’Brien, G. E., Rodriguez, I., \& Pamelá, P. (2010). Toward equity through participation in Modeling Instruction in introductory university physics. Physical Review Special Topics-Physics Education Research, 6(1), 010106.

Creswell, J. W., \& Creswell, J. D. (2017). Research design: Qualitative, quantitative, and mixed methods approaches. Sage publications.

Halloun, I. A. (2007). Modeling theory in science education (Vol. 24). Springer Science \& Business Media.

Helmi, M. L. (2011). Pengaruh Penggunaan Metode Pemodelan terhadap Peningkatan Pemahaman Konsep Fisika Ditinjau dari Pengetahuan Awal Siswa Kelas X SMA Negeri 1 Jember Tahun Pelajaran 20092010.(Tesis). DISERTASI dan TESIS Program Pascasarjana UM.

Hamdani, S. (2007). Deskripsi miskonsepsi siswa kelas VIII SMP Negeri 2 Pontianak tentang getaran. Skripsi). Pontianak: FKIP UNTAN.

Hestenes, D. (1987). Toward a modeling theory of physics instruction. American journal of physics, 55(5), 440-454.

Hestenes, D. (1997, March). Modeling methodology for physics teachers. In AIP conference proceedings (Vol. 399, No. 1, pp. 935-958). American Institute of Physics.

Jackson, J., Dukerich, L., \& Hestenes, D. (2008). Modeling Instruction: An Effective Model for Science Education. Science Educator, 17(1), 10-17.

Kiftiyah, N. I. M. (2014). Identifikasi Pemahaman Materi Konsep Siswa Kelas VIII SMP Negeri 4 Malang Semester II Dalam Materi Getaran dan Gelombang Tahun Ajaran 2013/2014. SKRIPSI Jurusan FisikaFakultas MIPA UM.

Meltzer, D. E., \& Manivannan, K. (2002). Transforming the lecture-hall environment: The fully interactive physics lecture. American Journal of Physics, 70(6), 639-654.

Morgan, G. A., Leech, N. L., Gloeckner, G. W., \& Barrett, K. C. (2004). SPSS for introductory statistics: Use and interpretation. Psychology Press.

National Research Council. (2012). A framework for K-12 science education: Practices, crosscutting concepts, and core ideas. National Academies Press.

Padang, Y.D., Munzil, \& Hidayat, A. (2016). Studi pemahaman konsep siswa pada materi getaran, gelombang dan bunyi. Prosiding Seminar Nasional Pembelajaran IPA. 489-491.

Indonesia, M. P. (2016). Peraturan Menteri Pendidikan dan Kebudayaan Republik Indonesia Nomor 24 Tahun 2016 tentang Kompetensi Inti dan Kompetensi Dasar Pelajaran pada Kurikulum 2013 pada Pendidikan Dasar dan Menengah. Jakarta: Menteri Pendidikan Dan Kebudayaan Republik Indonesia..

Ponimin, P. (2010). MEMADUKAN LABORATORIUM NYATA DAN MAYA DENGAN PENUGASAN SISWA BERBASIS MULTIMEDIA PADA PEMBELAJARAN GETARAN DAN GELOMBANG.Jurnal Penelitian Pembelajaran Fisika, 1(1).

Samiyah, S. (2015). pembelajaran learning cycle 5e pada materi getaran untuk meningkatkan pemahaman konsep siswa kelas VIII MTs sunan ampel pasuruan. SKRIPSI Jurusan Fisika-Fakultas MIPA UM.

Septa, D., \& Khoiri, N. (2010). Wayang sebagai media pembelajaran fisika untuk meningkatkan hasil belajar siswa pada pokok bahasan getaran dan gelombang pada siswa kelas VIII SMP Purnama 1 Semarang. Jurnal Penelitian Pembelajaran Fisika, 1(1).

Slavin, R. E. (2009). Psikologi pendidikan: Teori dan praktik edisi kesembilan jilid 1. Terjemahan M. Samosir. Educational psycology: Theory and practice,

Suswati, E. (2012). Pengaruh Pembelajaran Pemodelan terhadap Hasil Belajar Ditinjau dari Kemampuan Berpikir Kreatif Siswa Kelas X SMA Negeri 3 Balikpapan.(Tesis). DISERTASI dan TESIS Program Pascasarjana UM. 
Waldrip, B. (2014). IMPACT OF A REPRESENTATIONAL APPROACH ON STUDENTS'REASONING AND CONCEPTUAL UNDERSTANDING IN LEARNING MECHANICS. International Journal of Science and Mathematics Education, 12(4), 741-765.

Sutopo. (2012). Kecenderungan over-generalize penggunaan prinsip kolom udara/ pipa organa dalam analisis frekuensi sumber bunyi. Prosiding Seminar Nasional MIPA dan Pembelajaran. 824-831.

Isa, A. (2010). Keefektifan pembelajaran berbantuan multimedia menggunakan metode inkuiri terbimbing untuk meningkatkan minat dan pemahaman siswa. Jurnal Pendidikan Fisika Indonesia, 6(1).

Wells, M., Hestenes, D., \& Swackhamer, G. (1995). A modeling method for high school physics instruction. American journal of physics, 63(7), 606-619.

Widiastuti, A. \& Yulianti, E. (2016). Penerapan pembelajaran kooperatif model think pair share (tps) untuk meningkatkan penguasaan konsep dan aktivitas belajar ipa siswa klas ixf smp negeri 1 lekok tahun 2016. Prosiding Seminar Nasional Pembelajaran IPA. 266-269.

Windasari, A. I. (2017). Pembelajaran dengan Pemodelan untuk Meningkatkan Pemahaman Konsep Siswa Kelas X pada Topik Prinsip Archimedes. SKRIPSI Jurusan Fisika-Fakultas MIPA UM. 